\title{
Antiobesity, hypolipidemic, antioxidant and hepatoprotective effects of Achyranthes aspera seed saponins in high cholesterol fed albino rats
}

\author{
Naveed Khan ${ }^{1}$, Muhammad Shoaib Akhtarr ${ }^{1}$, Barkat Ali Khan²,3, Valdir de Andrade Braga ${ }^{4}$, Adam Reich ${ }^{5}$
}

\author{
${ }^{1}$ Faculty of Pharmacy, University of Sargodha, Sargodha, Pakistan \\ 2Department of Pharmacy, Faculty of Pharmacy and Alternative Medicine, \\ The Islamia University of Bahawalpur, Bahawalpur, Pakistan \\ ${ }^{3}$ Department of Pharmaceutics, Faculty of Pharmacy, Gomal University D.I. Khan, \\ Khyber Pakhtoon Khwa, Pakistan \\ ${ }^{4}$ Biotechnology Center Federal, University of Paraiba, Paraiba, Brazil \\ ${ }^{5}$ Department of Dermatology, Venereology and Allergology, Wroclaw Medical \\ University, Wroclaw, Poland
}

Submitted: 21 January 2014

Accepted: 6 May 2014

Arch Med Sci 2015; 11, 6: 1261-1271

DOI: 10.5114 /aoms.2015.56353

Copyright @ 2015 Termedia \& Banach

\section{Abstract}

Introduction: Numerous herbal medicines have been recommended for the treatment of different diseases. Achyranthes aspera, Linn. (Family: Amaranthaceae), popularly known as Charchitta or Pitpapra, is commonly used by traditional healers for the treatment of fever, malaria, dysentery, asthma, arterial hypertension, pneumonia, and diabetes. The root extract is well reputed for its insect molting hormonal activity. This investigation was conducted to evaluate the effects of saponins from Achyranthes aspera seeds on the serum lipid profile of albino rats fed a high cholesterol diet.

Material and methods: Hypolipidemic, antioxidant and hepatoprotective activities of these saponins were tested as described previously. To determine the mechanism underlying the observed effects, serum antioxidant status was assessed according to ABTS (2,2'-azino-bis-3-ethylbenzo-thiazoline-6-sulfonic acid), superoxide dismutase and ferric ion reducing antioxidant power (FRAP) assays in saponin-treated hyperlipidemic animals. Liver enzyme levels were determined to reveal any possible hepatotoxicity.

Results: Four-week oral administration of $A$. aspera seed saponins produced a significant $(p<0.05)$ decrease of total cholesterol, total triglycerides and LDL-C and a significant increase of HDL-C level in hyperlipidemic rats. Treatment with $A$. aspera seed saponins also showed a significant $(p<0.01)$ improvement of serum antioxidant status in tested animals. No significant hepatotoxicity was produced by such treatment as the serum liver enzyme activity remained unaltered.

Conclusions: Saponins from A. aspera seeds possess antihyperlipidemic and antioxidant properties which might lead to improvement of serum lipid profile and blood antioxidant status. Our findings support the folkloric use of this indigenous plant in the treatment of hyperlipidemia. However, its exact mechanism of action remains to be elucidated.

Key words: hyperlipidemia, antioxidant, hepatoprotection, Achyranthes aspera, ABTS, high cholesterol diet.

\author{
Corresponding author: \\ Barkat Ali Khan \\ Faculty of Pharmacy \\ University of Sargodha \\ Sargodha, Pakistan \\ E-mail: barki.gold@gmail.com, \\ Barkat.khan@gu.edu.pk
}




\section{Introduction}

Hyperlipidemia has been defined as abnormally elevated lipids or lipoproteins in the blood. Hyperlipidemia is nowadays a major health problem faced by many societies, which concerns health professionals, since it constitutes one of the major risk factors for the development of cardiovascular disease [1]. It has been reported that atherosclerosis and coronary heart disease are mainly caused by hyperlipidemia [2, 3]. Over the past decades atherosclerosis-related diseases diminished but they still account for significant morbidity and mortality in many middle aged and elderly people [4]. In respect of hyperlipidemia, recent interest has been focused on strategies that could enhance the removal of reactive oxygen species (ROS), by using either natural antioxidants or drugs that have the capacity to enhance the endogenous antioxidant system [5]. The antioxidant defense system is driven by different antioxidant mechanisms, for which plants have different groups of compounds, namely preventive antioxidants (enzymes such as catalases or peroxidases), radical scavenging compounds (ascorbic acid or carotenoids), and enzymes repairing DNA material. In the group of antioxidant and free radical scavenging agents, plants synthesize different compounds, principally phenolic derivatives, such as flavonoids, phenylpropanoids, stilbenes and many others. These compounds are also potential antioxidant agents for humans, protecting us from the damage caused by reactive oxygen species (ROS) [6]. Due to the growing interest in free radical technology, the importance of naturally occurring antioxidants cannot be ignored, as the safety of synthetic antioxidants such as butylated hydroxytoluene $(\mathrm{BHT})$, butylated hydroxyanisole (BHA), tertiary butylhydroquinone (TBHQ), gallic acid esters, etc. remains questionable. Moreover, these antioxidants have poor solubility and usually only show moderate antioxidant activity $[7,8]$.

Some preliminary studies have shown that A. aspera seed contains saponins (glycosides of oleanolic acid) A and B, which might exert an antiobesity effect in albino mice by reducing the excess accumulation of body fat and changing the serum lipid profile $[9,10]$.

In the light of previous research works the present investigation was carried out to more precisely evaluate the possible hypolipidemic and antiobesity activity of indigenous plant $A$. aspera seed saponins that have been used for centuries to treat various diseases. It is a very common weed of waste places and road sides in Pakistan.

\section{Material and methods}

\section{Plant material}

The ripe seeds of $A$. aspera locally known as Puthkanda were collected from various gardens and grazing areas of Islamabad between September and October, 2009. Seeds were authenticated and identified by the Department of Biological Sciences, University of Sargodha, Sargodha and the specimen was deposited in the departmental herbarium. The seeds were completely dried in the shade and were finally powdered with a Chinese herbal grinder. The powdered seeds were stored in closed cellophane bags at $4^{\circ} \mathrm{C}$ in a refrigerator until further analysis.

\section{Experimental animals}

Albino rats of both sexes, aged 3-4 months and weighing around 250-300 g, were used. The animals were kept in an animal room with an alternate light and dark cycle of $12 \mathrm{~h}$ (temperature $25 \pm 2^{\circ} \mathrm{C}$ ). Standard diet and fresh water was supplied ad libitum. The study was conducted in accordance with Good Laboratory Practices (GLP) regulations of the WHO. The principles of laboratory animal care of the National Institute of Health $(\mathrm{NIH})$ were followed in the study. The study protocol was approved by the institutional ethic committee.

Forty-eight rats were randomly divided into eight groups of six animals each $(\mathrm{A}-\mathrm{H}$ : normal control, negative control, five groups treated with saponins and another one treated with atorvastatin - positive control) and given free access to a high cholesterol diet (HCD) ad libitum. The food and water intake by each group was monitored at least twice weekly. The HCD was made from preformed cholesterol powder, butter, soybean oil and liver extract. A description of each group is shown in Table I. Body weight (g) and nasoanal length $\left(\mathrm{cm}^{2}\right)$ were measured at the start of the experiment, after 14 and 28 days, both in normal and HCD treated animals. Body mass index (BMI) was calculated by dividing the body weight (in g) by square of nasoanal length (in $\mathrm{cm}^{2}$ ).

\section{Detection, extraction and isolation of saponins}

Ten grams of powdered $A$. aspera seeds were extracted with $50 \mathrm{ml}$ of hot water and filtered. Five $\mathrm{ml}$ of the above filtrate was added to a test tube (Pyrex, Germany) containing $5 \mathrm{ml}$ of $1.8 \%$ $\mathrm{NaCl}$ solution; $5 \mathrm{ml}$ of distilled water was added to another tube with $5 \mathrm{ml}$ of $1.8 \% \mathrm{NaCl}$ solution (blank tube). Next, 8 drops of blood were added to both tubes - hemolysis occurred in the test tube containing the extract, indicating the presence of saponins, while no hemolysis was seen in the blank tube.

Fifty grams of powdered $A$. aspera seeds were incubated with $1000 \mathrm{ml}$ of $2 \mathrm{~N}$ hydrochloric acid for $2 \mathrm{~h}$ and filtered. Residues were neutralized by passing $4 \%$ ammonium hydroxide solution 


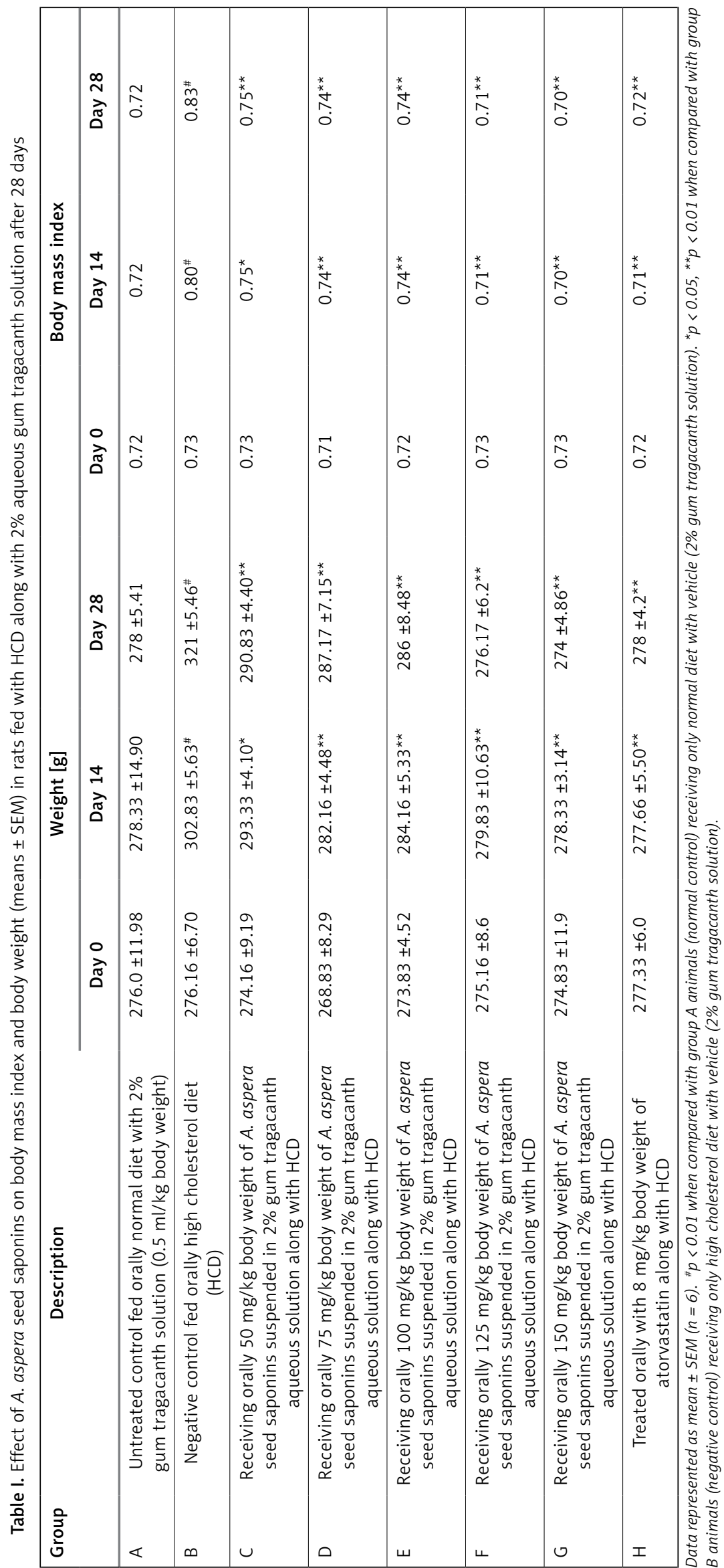


through the filtrate, dried and filtered with a paper at $60^{\circ} \mathrm{C}$ for $16 \mathrm{~h}$. The dry residues were next packed into a Soxhlet thimble and extracted with petroleum ether (Sigma Aldrich Chemicals, USA) at $40-60^{\circ} \mathrm{C}$ for $2 \mathrm{~h}$. The solvent was reduced to $30 \mathrm{ml}$ and placed in a cool place. Finally, saponins were precipitated with acetone (Sigma Aldrich Chemicals, USA). The exact identification of saponins was described elsewhere [11].

\section{Preparation of plant drug suspensions and induction of hyperlipidemia}

The saponins were triturated with a $2 \%$ aqueous gum tragacanth solution and the final volume was made up to $20 \mathrm{ml}$ to obtain a suitable concentration of saponins per $\mathrm{ml}$ for oral administration. Then the plant drug suspension was administered orally to each animal for investigation of the antihyperlipidemic and antioxidant effects. As a control atorvastatin was also administered after suspension in $2 \%$ aqueous gum tragacanth solution. Hyperlipidemia was induced by oral administration of a high cholesterol diet with preformed cholesterol powder, butter and liver extract.

\section{Collection of blood samples and estimation of blood lipid profile}

Blood samples were collected from the animals one hour after administration of the drugs under mild ether anesthesia at the $14^{\text {th }}$ and $28^{\text {th }}$ day of the study. For the estimation of biochemical parameters blood samples were centrifuged at $3500 \mathrm{rpm}$ for $20 \mathrm{~min}$ and the serum was stored at $-20^{\circ} \mathrm{C}$ until further analysis.

The blood lipid profile included total cholesterol (TC), triglycerides (TG), high-density lipoprotein cholesterol (HDL-C) and low-density lipoprotein cholesterol (LDL-C). The above blood lipid parameters were determined with the help of reagent kits by Fluitest, Analyticon (Biotechnologies AG, Germany) (Stat fax 3300, Awareness Technology, USA). The LDL-C and very-low-density lipoprotein (VLDL) levels were calculated using the following formulae: $\mathrm{LDL}=\mathrm{TC}-\mathrm{TG} / 5-\mathrm{HDL}, \mathrm{VLDL}=\mathrm{TC}-(\mathrm{HDL}+\mathrm{LDL})$.

\section{Antioxidant assays}

\section{Ferric ion reducing antioxidant power (FRAP) assay}

The oxidant in the FRAP assay was prepared by mixing 2,4,6-tripyridyl-s-triazine (TPTZ), acetate buffer and ferric chloride monohydrate. The conglomerate was referred to as "FRAP reagent". The final solution contained $1.67 \mathrm{mM}$ of Fe(III) and $0.83 \mathrm{mM}$ of TPTZ. To measure the FRAP value, $300 \mu \mathrm{l}$ of freshly prepared FRAP reagent was warmed up at $37^{\circ} \mathrm{C}$, a blank reading was taken at $\lambda=593 \mathrm{~nm}$, and then $30 \mu \mathrm{l}$ of tested sample and $30 \mu \mathrm{l}$ of pure water were added. The absorbance reading was taken at $\lambda=593 \mathrm{~nm}[12,13]$.

\section{Determination of ABTS cation radical decolorization assay}

ABTS, the oxidant, was produced by persulfate oxidation of 2,2'azinobis (3-ethylbenzothiazoline-6-sulfonic acid). This solution was diluted with phosphate buffer $(\mathrm{pH}=7.4)$ until the absorbance reached 0.7 to 0.8 at $\lambda=734 \mathrm{~nm}$. One $\mathrm{ml}$ of the resulting solution was mixed with the sample and the absorbance was read after mixing for $4 \mathrm{~min}$ at $30^{\circ} \mathrm{C}$. The difference of the absorbance reading was plotted versus the antioxidant concentrations to give a straight line [13, 14].

\section{Oxygen scavenging capacity assay (SOD)}

The activity of SOD was assayed by using an assay mixture composed of $1.2 \mathrm{ml}$ of $0.025 \mathrm{mmol} / \mathrm{l}$ sodium pyrophosphate buffer $(\mathrm{pH}=8.3), 0.1 \mathrm{ml}$ of phenazine methosulfate $(186 \mathrm{mmol} / \mathrm{l})$, appropriately diluted enzyme stock solution and water given to a total volume of $3 \mathrm{ml}$. After incubation at $30^{\circ} \mathrm{C}$ for $90 \mathrm{~s}$, the reaction mixture was vigorously stirred and mixed with $4 \mathrm{ml}$ of $n$-butanol. The color intensity of the chromatogram in the butanol layer was measured at $\lambda=540 \mathrm{~nm}$ against $n$-butanol $[13,14]$.

\section{Determination of serum hepatic enzymes}

The serum hepatic biochemical parameters such as aspartate aminotransferase (AST) and alanine aminotransferase (ALT) were estimated using an enzymatic test kit (Fluitest) and a chemistry analyzer (Stat fax 3300, Awareness Technology, USA).

\section{Statistical analysis}

The statistical tool GraphPad Prism 4 (GraphPad Software, USA) was used. The data were expressed as mean \pm S.E.M (standard error of mean). Data were analyzed using one-way ANOVA, followed by Dennett's multiple-comparison test. The $I C_{50}$ values were calculated. The level of significance was set at $p<0.05$.

\section{Results}

\section{Effects of Achyranthes aspera seed saponins on body mass index (BMI) of high cholesterol diet (HCD) fed rats}

Table I shows BMI (means \pm SEM) at the starting day of HCD administration and after 14 days. In the untreated control group A (receiving only $2 \%$ aqueous gum tragacanth solution) a non-significant $(p>0.05) \mathrm{BMI}$ change was observed. In con- 
trast, a significant increase of BMI $(p<0.01)$ was observed in group B receiving HCD for 2 weeks. In groups $\mathrm{C}, \mathrm{D}$, and $\mathrm{E}$ treated with lower doses of saponins from $A$. aspera, HCD also caused a significant $(p<0.05)$, albeit much smaller, increase of body weight. However, the BMI change was significant $(p<0.05)$ in groups $F$ and $G$ receiving high doses of saponins, as compared to group B, showing a dose-dependent decrease in BMI due to $A$. aspera seed saponins (Table I).

Regarding the results at day 28 , no further increase of BMI was found in groups $C$ to $G$ treated with HCD along with the saponins. Remarkably, an additional highly significant $(p<0.01)$ increase of $\mathrm{BMI}$ was found in group $\mathrm{B}$ as compared with group A. The cumulative water and food intake was almost the same in all analyzed groups of animals and no change during the study was observed (data not shown).

\section{Effects of Achyranthes aspera seed saponins on lipid profile}

Administration of HCD to albino rats resulted in a significant $(p<0.05)$ increase of TC, TG, LDL-C and VLDL-C and a decrease of HDL-C levels in rats from group $B$, compared to the rats fed with a normal diet at the $14^{\text {th }}$ and $28^{\text {th }}$ day of our study. The LDL-C/HDL-C ratio was also found to be increased significantly $(p<0.05)$ (Figure 1$)$. Dose-dependent protective effects of saponins isolated from $A$. aspera on blood serum lipid profile were noted after 14 days of treatment, as shown in Figure 1. Oral administration of $A$. aspera seed saponins significantly lowered the serum cholesterol level as compared to control animals only receiving HCD (Figure 1).

Administration of saponins of $A$. aspera for 28 consecutive days maintained the achieved improvement of lipid profile in a dose-dependent manner, compared to group B. The beneficial results of high saponin doses were comparable with the control standard drug (atorvastatin) on the $28^{\text {th }}$ day of treatment (Figure 1 ).

\section{Effects of Achyranthes aspera seed saponins on serum antioxidant status}

Antioxidant activity of saponins of $A$. aspera seeds was judged by ABTS, FRAP and SOD assays. Administration of saponins of $A$. aspera seeds in different doses effectively acted as free radical scavengers, and demonstrated significant $(p<0.01)$ antioxidant activity (Figure 2). Administration of A. aspera seed saponins along with a high cholesterol diet caused a significant, dose-dependent improvement of the serum antioxidant status of treated rats. The FRAP content was reduced, whereas SOD and ABTS contents were significantly improved (Figure 2).

\section{Effects of saponins of Achyranthes aspera on hepatic functions}

To evaluate the hepatic status of rats treated with HCD and also any alteration due to oral administration of saponins from $A$. aspera for 28 days, AST and ALT were measured. Our results indicated mild hepatoprotective potential of saponins from $A$. aspera against HCD, as shown in Table I.

\section{Discussion}

All over the globe the incidence of hyperlipidemia increases day by day either due to genetic mutations or unhealthy life style or secondarily due to other diseases $[15,16]$ and is becoming one of the major causes of death [17]. Pakistan is also facing the same threat [18]. Researchers have paid attention to natural sources to find new agents with hypolipidemic activity and having minimal side effects, as therapy with commercially available lipid-lowering drugs is often associated with significant side effects. Achyranthes aspera possesses potent antifungal, antifertility, antihyperlipidemic, antidiabetic, immunomodulatory, anticarcinogenic, diuretic, cardiotonic, anti-inflammatory, analgesic, and antibacterial activities [19]. The present study was conducted to evaluate the antiobesity, hypolipidemic and antioxidant effects of $A$. aspera seed saponins in hyperlipidemic albino rats.

Obesity is a major problem and can lead to many complications including hypertension, diabetes, myocardial infarction, etc. A vast range of natural products and medicinal plants, including crude extracts and isolated compounds from plants, can be used to induce weight loss and prevent diet-induced obesity. It has been reported that obesity can be improved by various mechanisms, i.e. by inhibition of lipase activity or delaying lipid absorption [20]. It has also been observed that dietary lipids are not directly absorbed from the intestine unless they have been subjected to the action of pancreatic lipases. Inhibition of these digestive enzymes might be beneficial in the treatment of obesity. Although cumulative food intake was in our study similar in all groups, animals from group $B$ showed a significant increase of body weight and BMI after consumption of HCD for a 4-week experimental period when compared to the normal diet group, duly supporting the idea that a high-fat diet may produce a marked increase in body weight and BMI compared with a normal diet [21-23]. It has been established that overnutrition from high calorie and fatty diets induces lipo- and glucotoxicity, by increasing oxidative stress due to mitochondrial dysfunction with ROS overproduction, triggering the proinflammatory cascade, and potentiating tissue damage by 


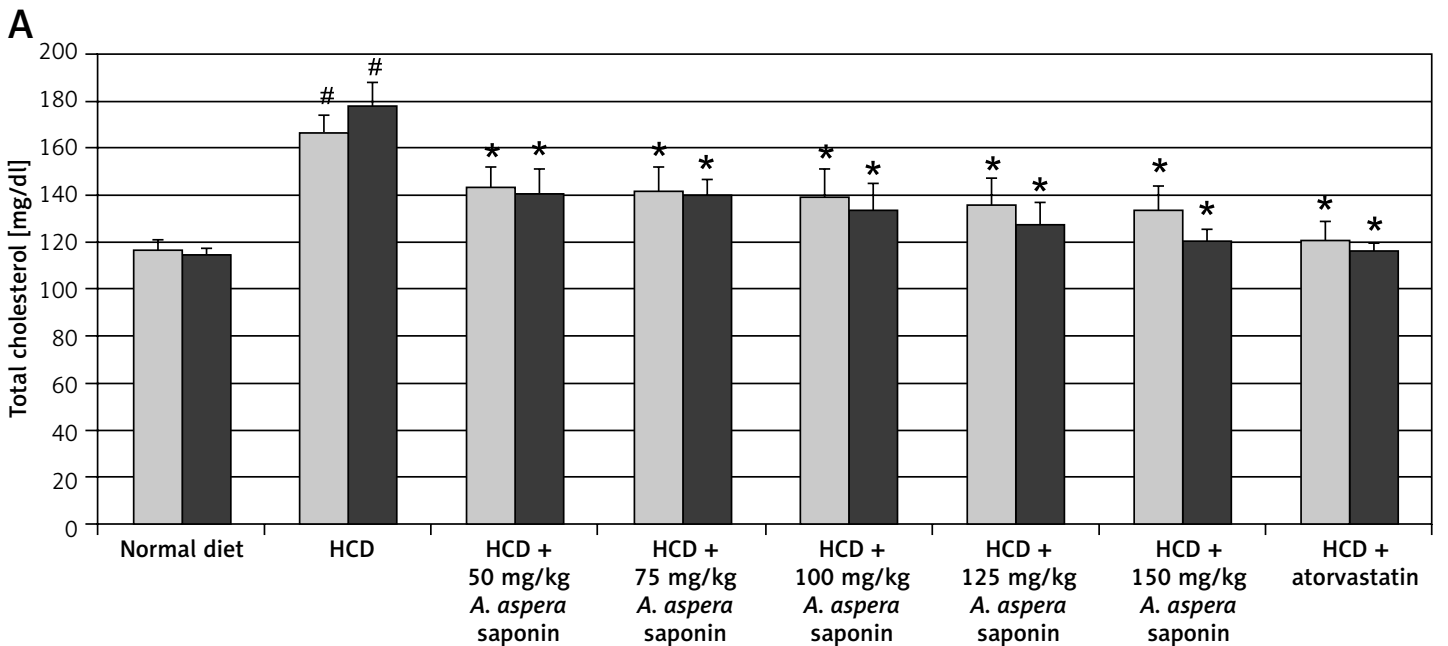

B

$\square$ Day $14 \quad \square$ Day 28

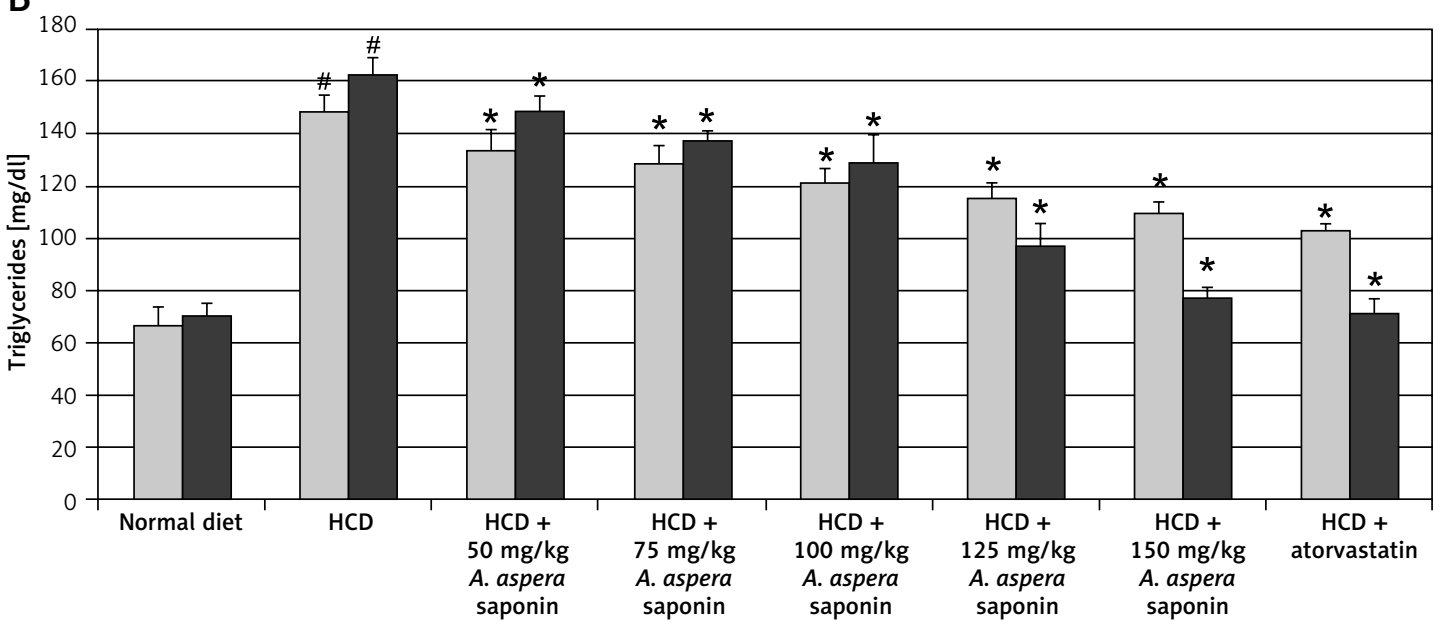

$\square$ Day 14

$\square$ Day 28

C

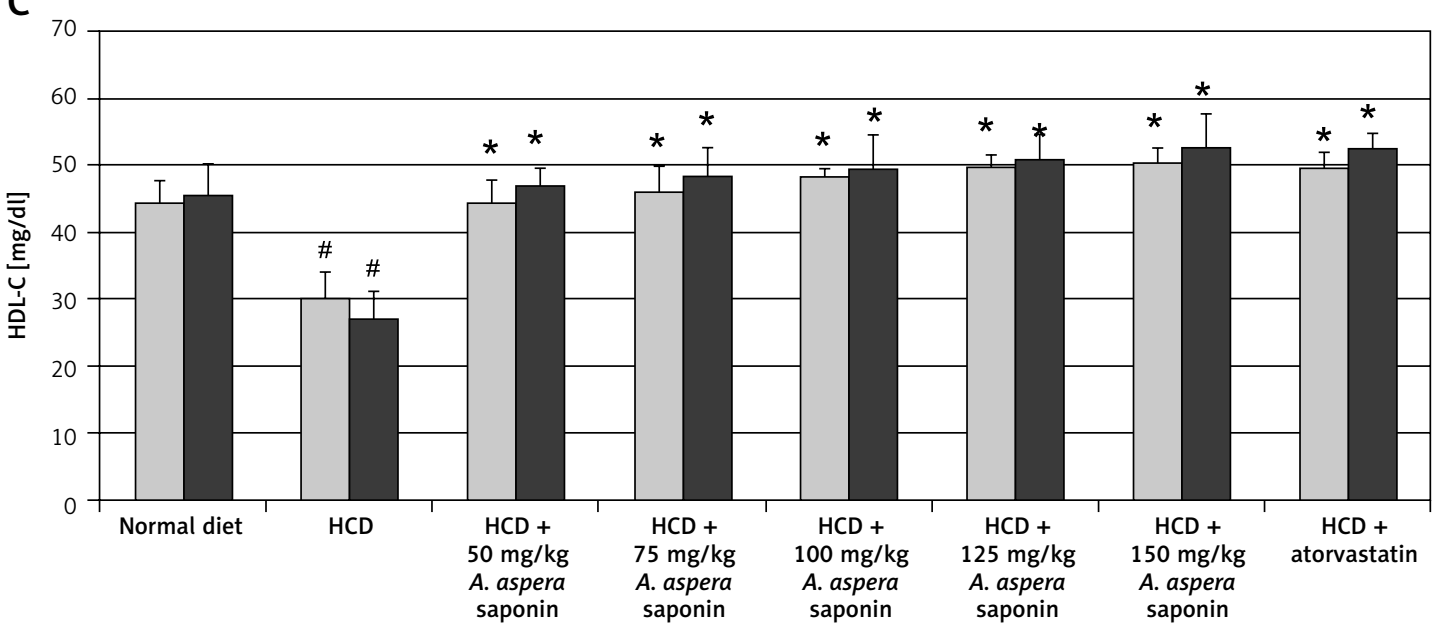

$\square$ Day 14

$\square$ Day 28

Figure 1. Mean total blood serum lipid parameters (mean $\mathrm{mg} / \mathrm{dl} \pm \mathrm{SEM}, n=6$ ) on the $14^{\text {th }}$ and $28^{\text {th }}$ day after starting oral administration of 50, 75, 100, 125 and $150 \mathrm{mg}$ of Achyranthes aspera seed saponins with high cholesterol diet (HCD) treated rats in comparison to normally, HCD and HCD + atorvastatin treated control rats ( ${ }^{\#} p<0.05$ when compared with control receiving only normal diet with vehicle ( $2 \%$ gum tragacanth solution); ${ }^{*} p<0.05$ when compared with animals receiving only high cholesterol diet with $2 \%$ gum tragacanth solution) 
D

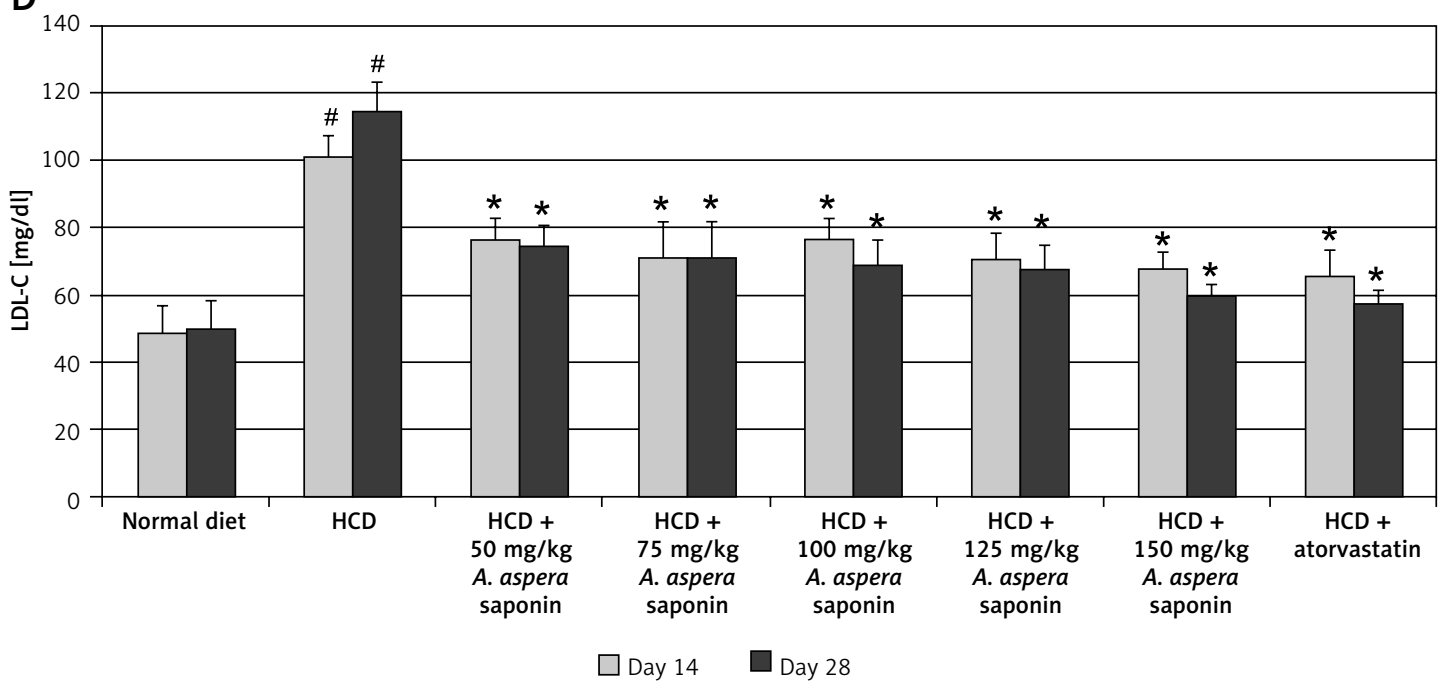

E

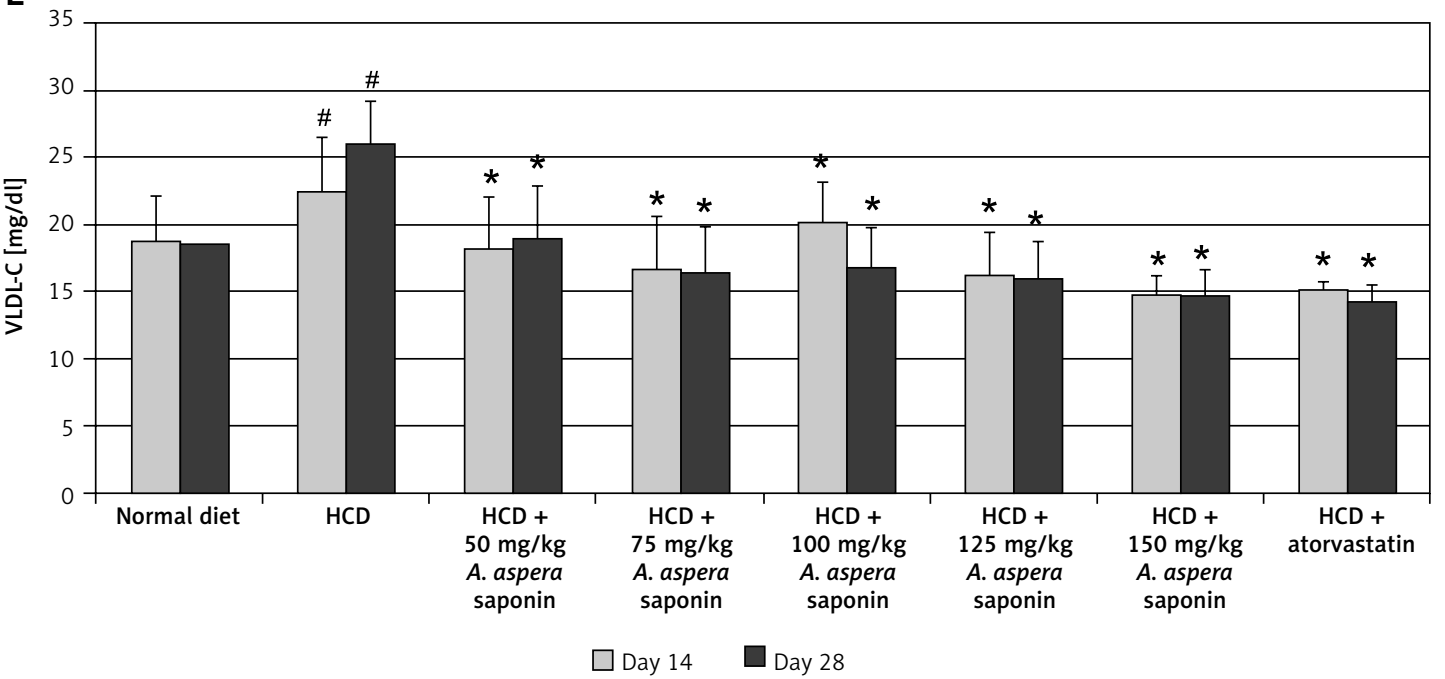

F

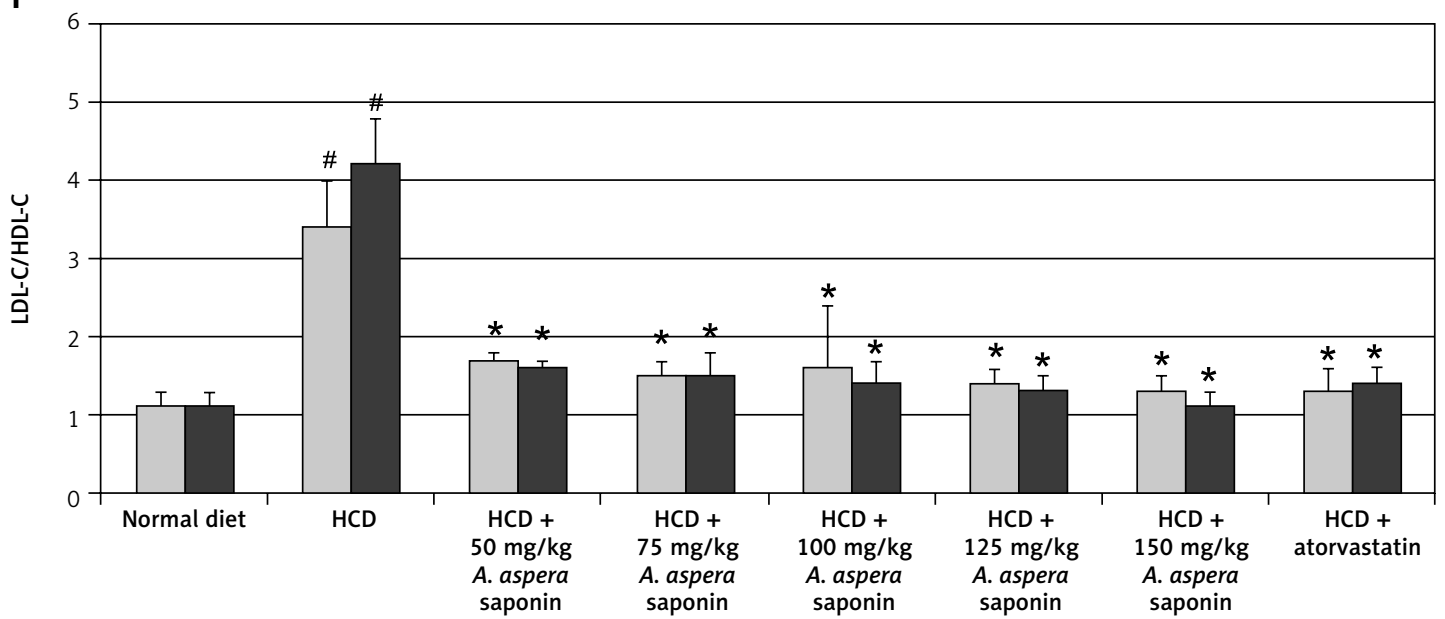

$\square$ Day 14

Day 28

Figure 1. Cont. 

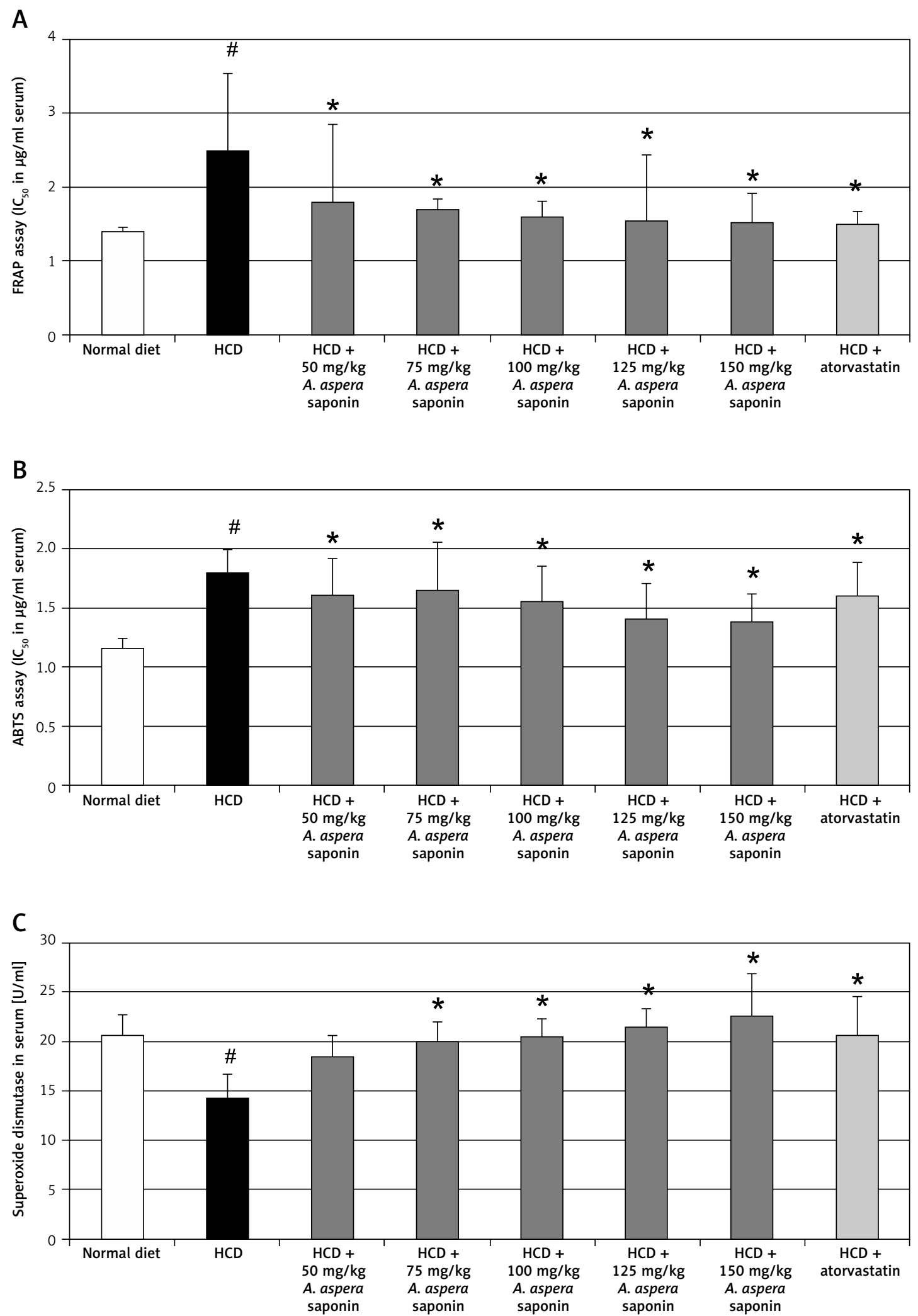

Figure 2. Mean blood serum antioxidant profile (means $\pm \mathrm{SEM}, n=6$ ) on the $28^{\text {th }}$ day after oral administration of $50,75,100,125$ and $150 \mathrm{mg}$ of $A$. aspera seed saponins with high cholesterol diet (HCD) in comparison to normally, $\mathrm{HCD}$ and $\mathrm{HCD}+$ atorvastatin treated control rats $(\# p<0.05$, when compared with normal control receiving only normal diet with vehicle ( $2 \%$ gum tragacanth solution), ${ }^{*} p<0.05$ when compared with the control receiving only high cholesterol diet with $2 \%$ gum tragacanth solution) 
altered production of proinflammatory mediators from white adipose tissue (WAT) due to increased fat accumulation. Thus, it is nowadays believed that oxidative stress and inflammation coexist in obesity and that they should be ameliorated to prevent adverse outcomes such as fat accumulation in WAT [24-28]. It can be speculated that A. aspera seed saponins contain some active principles which caused the decrease of body weight and $\mathrm{BMI}$ of treated rats. The anti-obesity effect of $A$. aspera seed saponins might thereby explain their advantageous effects on metabolism, i.e. lipid-lowering properties.

Lipid metabolism disorders have been reported as a widespread problem of modern civilization because they play a significant role in the development of generalized atherosclerosis. Increased serum concentrations of TC and TG have been reported as a meaningful abnormality as they are often associated with cardiovascular disorders and many other pathological syndromes. Both LDL and VLDL have a causative role in atherogenesis [29]. Treatment with saponins of $A$. aspera seeds significantly decreased the levels of TC, TG, LDL, VLDL, and LDL/HDL, whereas a significant increase was found in HDL-C.

Treatment with $A$. aspera seed saponins resulted in favorable changes of serum HDL-C, i.e. increased its level, which is currently recognized as a better atherosclerosis marker than each lipid parameter alone. It is possible that the hypolipidemic effects of $A$. aspera seeds may affect the reverse cholesterol transport of HDL. It has been established that HDL can be divided into two subclasses, HDL-2 and HDL-3; but still further studies are needed to determine the changes of these subclasses. Administering various doses of saponins of $A$. aspera seeds $(50,75,100,125,150 \mathrm{mg} /$ $\mathrm{kg}$ p.o.) to hypercholestrolemic rats for 4 weeks decreased the susceptibility of LDL-C to oxidation. A similar decrease of LDL-C also occurred on treatment with $8 \mathrm{mg} / \mathrm{kg}$ of atorvastatin, a standard therapy for hypercholesterolemia (Table II). Hypercholesterolemia and hypertriglyceridemia have been reported as major risk factors for atherosclerosis and related occlusive vascular diseases. Clinically relevant complications of atherosclerosis could be diminished and thus life prolonged when blood lipids are lowered by antihyperlipidemic/ hypolipidemic drugs. Increased serum concentration of TC and TG is a major lipid abnormality syndrome as they are often associated with cardiovascular disorders and many other pathological syndromes. In the present study, a significant fall of TG levels was noted in tested animals consecutively treated with saponins of $A$. aspera seeds at different doses for 28 days. It may be suggested that this decrease of TG levels may be due to en- hanced activity of lipases that hydrolyze TG under normal conditions or increased excretion of TG via feces. Whether the decrease of cholesterol level was due to reduction of resorption of endogenous cholesterol or an increase in the rate of secretion into the intestinal tract, or both, remains to be elucidated in the future. HDL-C has been reported to benefit the body in two ways: it removes cholesterol from the walls of arteries and returns it to the liver; and it helps to prevent oxidation of LDL-C. In fact, it appears to have antioxidant properties on its own. HDL-C then helps to keep arteries open and reduces the risk of heart attack. In contrast, preclinical observations demonstrated that hypercholesterolemia promotes accumulation of oxidatively modified low-density lipoprotein (Ox-LDL) in the arterial wall, promoting endothelial cell (EC) dysfunction and the development of atherosclerosis [30-32].

In the present study, atorvastatin was used as a positive control because it is a potent hypolipidemic drug and causes inhibition of 3-hydroxy-3-methyl-glutaryl coenzyme-A (HMG-CoA) reductase, the rate-limiting step in cholesterol biosynthesis. Increased atherosclerosis risk in hyperlipidemic patients may be a result of the enhanced oxidizability of their plasma lipoproteins. It has been shown that hypocholesterolemic drug therapy, including the HMG-CoA reductase inhibitors, and the hypotriglyceridemic drug bezafibrate, significantly reduced the enhanced susceptibility to oxidation of low-density lipoprotein (LDL) isolated from hyperlipidemic patients. Although this

Table II. Mean blood serum enzyme level (IU/dl \pm SEM) on $28^{\text {th }}$ day after starting oral administration of 50, 75, 100, 125 and $150 \mathrm{mg}$ of $A$. aspera seed saponins given with HCD in comparison to normally, HCD and HCD + atorvastatin treated control rats

\begin{tabular}{|lcc|}
\hline \multirow{2}{*}{$\begin{array}{l}\text { Treatment } \\
\text { group }\end{array}$} & \multicolumn{2}{c|}{ Serum hepatic parameters } \\
\cline { 2 - 3 } & AST [IU/dI] & ALT [IU/dI] \\
\hline A & $60.57 \pm 2.99$ & $18 \pm 1.98$ \\
\hline B & $77.77 \pm 3.4^{\#}$ & $24.14 \pm 3.18^{\#}$ \\
\hline C & $65.71 \pm 6.04^{*}$ & $23.14 \pm 3.07^{*}$ \\
\hline D & $64 \pm 4.86^{* *}$ & $20.57 \pm 3.86^{* *}$ \\
\hline E & $72.43 \pm 5.99$ & $19.29 \pm 1.80^{* *}$ \\
\hline F & $70.86 \pm 7.55^{*}$ & $21.29 \pm 2.70^{*}$ \\
\hline G & $68.29 \pm 6.18^{*}$ & $20.43 \pm 2.50^{* *}$ \\
\hline H & $70.71 \pm 5.64^{*}$ & $21.57 \pm 4.35^{*}$ \\
\hline
\end{tabular}

Data represented as mean \pm SEM $(n=6) .{ }^{*} p<0.05$, "\#p $p<0.01$ when compared with group $A$ animals (normal control) receiving only normal diet with vehicle ( $2 \%$ gum tragacanth solution). ${ }^{*} p<0.05$, ${ }^{* *} p<0.01$ when compared with group $B$ animals (negative control) receiving only high cholesterol diet with vehicle (2\% gum tragacanth solution). 
antioxidative effect could not be obtained in vitro with all of these drugs, it seems that active drug metabolites, which are formed in vivo, could affect lipoprotein oxidizability [32, 33].

It has been reported that hypercholesterolemia leads to increased production of reactive oxygen species (ROS), which cause lipid peroxidation. Reactive oxygen species initiate a series of chain reactions in vivo and ultimately damage tissue and DNA. Superoxide dismutase and catalase have been reported as major enzymes that play an important role in the elimination of reactive oxygen species producing oxidative damage [34, 35]. Antioxidants are compounds capable of donating a single electron or hydrogen atom for reduction [36]. Antioxidant effects of saponins of $A$. aspera have been investigated in terms of ABTS, FRAP and SOD assay both in control and treated rats. Significant improvement was observed in the antioxidant status of the serum of rats treated with saponins of A. aspera seeds, i.e. by considerable improvement of FRAP and ABTS levels and increase of SOD. Higher FRAP values give higher antioxidant capacity because the FRAP value is based on reducing ferric ion, where antioxidants are the reducing agent. To conclude, $A$. aspera seed saponins appeared to ameliorate the oxidative damage, probably due to the presence of phenolic and flavonoids.

To evaluate the effect of consumption of HCD and saponins of $A$. aspera on the hepatic status of animals, serum AST and ALT were measured. It was found that saponins of $A$. aspera have no hepatotoxic effect but instead they possess hepatoprotective potential by normalizing the levels of serum AST and ALT in HCD-treated rats.

In conclusion, the results of the present investigation clearly indicate that saponins of $A$. aspera seeds possess hypolipidemic properties showing hypotriglyceridemic or hypocholesterolemic effects with undetectable side effects on liver and cardiac functions. Due to the significant effect on lipid profile, research is still ongoing to investigate the same hypolipidemic activity of different extracts from seed powder. This may lead to activity-guided fractionation of that particular extract in order to better know the phytochemical composition, isolation methods, and structure elucidation of some of the bioactive constituents followed by establishing the most probable mechanism of action of reducing serum lipids.

Based on the above results, we propose that A. aspera seed saponins, if properly formulated, may be used as potent hypolipidemic agents also showing beneficial antioxidant and hepatoprotective properties.

\section{Conflict of interest}

The authors declare no conflict of interest.

\section{References}

1. Braunwald E. Shattuck lecture - cardiovascular medicine at the turn of the millennium: triumphs, concerns, and opportunities. N Engl J Med 1997; 337: 1360-9.

2. Mahley RW, Weisgraber KH, Farese RV Jr. Disorders of lipid metabolism. In: Larsen PR, Kronenberg HM, Melmed S, Polonsky KS (eds.). Williams textbook of endocrinology. 10th ed. Saunders, Philadelphia (PA), 2003; 1642-1705.

3. Burchardt P, Zurawski J, Zuchowski B, et al. Low-density lipoprotein, its susceptibility to oxidation and the role of lipoprotein-associated phospholipase A2 and carboxyl ester lipase lipases in atherosclerotic plaque formation. Arch Med Sci 2013; 9: 151-8.

4. Bhatnagar D, Soran H, Durrington PN. Hypercholesterolaemia and its management. Br Med J 2008; 337: a993.

5. McCord JM. Therapeutic control of free radicals. Drug Discov Today 2004; 9: 781-2.

6. Amira S, Dade M, Schinella G, Rios J. Anti-inflammatory, anti-oxidant, and apoptotic activities of four plant species used in folk medicine in the Mediterranean basin. Pak J Pharm Sci 2012; 25: 65-72.

7. Barlow SM. Toxicological aspects of antioxidants used as food additives. In: Food antoxidants. Hudson BJF (eds.). Elsevier, London 1990; 253-307.

8. Branen AL. Toxicology and biochemistry of butylated hydroxyanisole and butylated hydroxytoluene. J Am Oil Chem Soc 1975; 52: 59-63.

9. Krishnakumari S, Priya K. Hypolipidemic efficacy of Achyranthes aspera on lipid profile in sesame oil fed rats. Anc Sci Life 2006; 25: 49-56.

10. Rani N, Sharma SK, Vasudeva N. Assessment of antiobesity potential of Achyranthes aspera Linn. seed. Evid Based Complement Alternat Med 2012; 2012: 715912.

11. Gokhale AB, Damre AS, Kulkami KR, Saraf MN. Preliminary evaluation of anti-inflammatory and anti-arthritic activity of S. lappa, A. speciosa and A. aspera. Phytomedicine 2002; 9: 433-7.

12. Gülçin I, Küfrevioglu OI, Oktay M, Büyükokuroglu ME. Antioxidant, antimicrobial, antiulcer and analgesic activities of nettle (Urtica dioica L.). J Ethnopharmacol 2004; 90: 205-15.

13. Huang D, Ou B, Prior RL. The chemistry behind antioxidant capacity assays. J Agric Food Chem 2005; 53 : 1841-56.

14. Pellegrini N, Del Rio D, Colombi B, Bianchi M, Brighenti F Application of the 2,2'-azinobis(3-ethylbenzothiazoline-6-sulfonic acid) radical cation assay to a flow injection system for the evaluation of antioxidant activity of some pure compounds and beverages. J Agric Food Chem 2003; 51: 260-4.

15. Arif M, Saify ZS, Rashid S, Ahmad M. Effect of newly synthesized compound on various serum lipid parameters. J Isl Acad Sci 1990; 3: 118-23.

16. El-Hazmi MA, Warsy AS. Prevalence of plasma lipid abnormalities in Saudi children. Ann Saudi Med 2001; 21: 21-5.

17. Parab RS, Mengi SA. Hypolipidemic activity of Acorus calamus L. in rats. Fitoterapia 2002; 73: 451-5.

18. Aziz K, Aziz S, Faruqui AMA, et al. Evaluation and comparison of coronary heart disease risk factor profiles of children in a country with developing economy. J Pak Med Assoc 2004; 54: 364-71.

19. Bhosale UA, Yegnanarayan R, Pophale PD, Zambare MR, Somani RS. Study of central nervous system depressant and behavioral activity of an ethanol extract of Achyranthes aspera (Agadha) in different animal models. Int J App Basic Med Res 2011; 1: 104-8. 
20. Padwal RS, Majumdar SR. Drug treatments for obesity: orlistat, sibutramine, and rimonabant. Lancet 2007; 369: 71-7.

21. Astrup A, Buemann B, Western P, Toubro S, Raben A, Christensen NJ. Obesity as an adaptation to a high-fat diet: evidence from a cross-sectional study. Am J Clin Nutr 1994; 59: 350-5.

22. Portillo MP, Simón E, García-Calonge MA, Del Barrio AS. Effect of high-fat diet on lypolisis in isolated adipocytes from visceral and subcutaneous WAT. Eur J Nutr 1999; 38: 177-82.

23. Rebuffé-Scrive M, Surwit R, Feinglos M, Kuhn C, Rodin J. Regional fat distribution and metabolism in a new mouse model (C57BL/6J) of non-insulin-dependent diabetes mellitus. Metabolism 1993; 42: 1405-9.

24. Dandona P, Aljada A, Bandyopadhyay A. Inflammation: the link between insulin resistance, obesity and diabetes. Trends Immunol 2004; 1: 4-7.

25. Aggarwal BB. Targeting inflammation-induced obesity and metabolic diseases by curcumin and other nutraceuticals. Annu Rev Nutr 2010; 30: 173-99.

26. German AJ, Ryan VH, German AC, Wood IS, Trayhurn P. Obesity, its associated disorders and the role of inflammatory adipokines in companion animals. Vet J 2010; 1: 4-9.

27. Tan DX, Manchester LC, Fuentes-Broto L, Paredes SD, Reiter RJ. Significance and application of melatonin in the regulation of brown adipose tissue metabolism: relation to human obesity. Obes Rev 2010; 12: 167-88.

28. Parthasarathy S, Quinn MT, Schwenke DC, Carew TE, Steinberg D. Oxidative modification of beta-very low density lipoprotein. Potential role in monocyte recruitment and foam cell formation. Arteriosclerosis 1989; 9: 398-404.

29. Frishman WH. Biologic markers as predictors of cardiovascular disease. Am J Med 1998; 104: 18S-27S.

30. Agil A, Navarro-Alarcón M, Ruiz R, Abuhamadah S, ElMir MY, Vázquez GF. Beneficial effects of melatonin on obesity and lipid profile in young Zucker diabetic fatty rats. J Pineal Res 2011; 50: 207-12.

31. Aikawa M, Libby P. The vulnerable atherosclerotic plaque: pathogenesis and therapeutic approach. Cardiovasc Pathol 2004; 13: 125-38.

32. Aviram M, Rosenblat M, Bisgaier CL, Newton RS. Atorvastatin and gemfibrozil metabolites, but not the parent drugs, are potent antioxidants against lipoprotein oxidation. Atherosclerosis 1998; 138: 271-80.

33. Chakraborty A, Brantner A, Mukainaka T, et al. Cancer chemopreventive activity of Achyranthes aspera leaves on Epstein-Barr virus activation and two-stage mouse skin carcinogenesis. Cancer Letters 2002; 177: 1-5.

34. Tahiliani P, Kar A. Achyranthes aspera elevates thyroid hormone levels and decreases hepatic lipid peroxidation in male rats. J Ethnopharmacol 2000; 71: 527-32.

35. Lyons TJ, Bailie KE, Dyer DG, Dunn JA, Baynes JW. Decrease in skin collagen glycation with improved glycemic control in patients with insulin-dependent diabetes mellitus. J Clin Invest 1991; 87: 1910-5.

36. Trocha M, Merwid-Lad A, Chlebda E, et al. Influence of ezetimibe on selected parameters of oxidative stress in rat liver subjected to ischemia/reperfusion. Arch Med Sci 2014; 10: 817-24. 